\title{
What if...? Imagining non-Western perspectives on pragmatic theory and practice
}

\author{
Felix K. Ameka \& Marina Terkourafi \\ Leiden University Centre for Linguistics
}

\begin{abstract}
To date, pragmatic theory and practice have largely drawn on theories and models based on observations of communicative practices in the West and tacitly treated as culturally neutral, while patterns of language use in non-Western communities have been used as testing grounds for Western usage rules and their assumed motivations. We see this practice as contrary to calls for cognitive justice and as hampering progress toward the development of inclusive and truly universally valid theories of pragmatics. We illustrate these points by discussing four themes which have been tested in non-Western languages: speech acts, conversational implicatures, (im)politeness, and Conversation Analysis. We then move on to the domain of research ethics and find that, here too, practices tend to reflect Western values, prioritizing Western notions of ethics and what is important to people and ultimately falling short of serving the needs both of the communities where the data are collected, and of the researchers themselves. We conclude with recommending three steps we can all take to make pragmatics a more inclusive discipline, respecting and reflecting patterns of language-in-use irrespective of where they are located geographically.
\end{abstract}

Núnyá, adidóé, así métunc o 'Knowledge is like a baobab tree, one person cannot embrace it'

Ewe proverb

\section{Introduction}

The Ewe proverb which is the epigraph of this paper likens knowledge to the huge baobab tree which cannot be embraced by one person or by a pair of hands. The moral lesson it contains is that no single person or perspective has monopoly over knowledge. This moral lesson resonates with calls for "cognitive justice" - that is, "the right of many forms of knowledge to exist, seeing that all knowledges are partial and complementary" (Visvanathan 2002: 7) - in scientific enquiry. In this context, our goal in this short article is to explore the possibilities for embracing theories and models of social interaction and language-in-use from diverse lingua-cultures, especially from the so-called non-Western world. How has this project been understood in the context of pragmatic inquiry until now, to what extent has it been carried out, and how (else) can it be understood? We hope to show that there are linguistic practices that are radically different from established views currently on offer in pragmatics and that, in the interest of cognitive justice and the plurality of sciences and knowledge systems, these should be developed to complement the current stock.

Before continuing with our task of reflecting on these non-Western perspectives, it is worth acknowledging that the task itself is framed from a Western perspective. It is often pointed out that non-Western is a vague and vast term. Does it include the Middle East? What about Eastern Europe? 'Fringe' areas like Mexico and Greece have been struggling with these 
questions since their modern inception. ${ }^{1}$ Fully aware of the issues here, our primary focus will be Africa (even here, there is enormous communicative diversity), although we will also draw parallels to other areas.

A useful way to begin thinking about our task is to reflect on a hypothetical question: What would linguistics (or any subdiscipline thereof, including pragmatics) look like, had it been based on African language practices and data? For one thing, multilingualism as a natural state of the human mind and in society would probably not have come as a late realization in the field as it has now. This being the norm rather than the exception in Africa (and in South Asia), models of multilingual and multilectal linguistic practices may have preceded (rendering them obsolete) the dominant monocultural and monolingual models, largely acknowledged to be reflections of standard language ideologies promoted within the nation-states of Europe. Perhaps we would also have a better model of multimodality where we pay attention to both the visual and auditory modes of language use, reduced use of non-verbal and gestural channels also known to be characteristic of some Western European modes of communication. Perhaps we would have a better handle on language use in various culturally recognized activities. We might, for instance, no longer claim that greetings are meaningless or used only for phatic communion. ${ }^{2}$ We might develop an understanding of greetings as not just greetings but rather as a type of activity in which ideologies relating to honor and status are enacted, as is the case in West Africa (see e.g. Finnegan 1969, Irvine 1974, Foley 1997, Ameka 2009).

There is no doubt that over the past half century much information has been gathered from the non-Western world about linguistic practices and the cultural logics that motivate them. Still, these other perspectives have yet to make their way into the mainstream of pragmatic theorizing. That is not to deny the existence of pragmatic frameworks rooted in the non-Western world, such as Emancipatory Pragmatics (Hanks et al. 2009, see also Ueno et al. in this issue) and Postcolonial Pragmatics (Anchimbe \& Janney 2011), both of which have been showcased through special issues of the Journal of Pragmatics. Despite their availability, however, few studies have been conducted within these frameworks. ${ }^{3}$ Admittedly, paradigm change in scientific practice is slow to materialize and these frameworks are recent but it is telling that, despite a recent boom in textbook and handbook publications in pragmatics, only one textbook (Senft 2014) mentions emancipatory pragmatics and only one handbook (Barron et al. 2017) includes a chapter on postcolonial pragmatics (Anchimbe \& Janney 2017). Our point is that, while the potential of these theories to positively impact the field as a whole has been acknowledged, ${ }^{4}$ uptake by the scientific community has been slow. If these theories are not used to train students and if scholars outside a select few are not exposed to them, there is a real danger that they will be, as it were, "museumized" and catalogued as alternative forms of knowledge (Visvanathan 2002: 184, 185), admired but not engaged with in the pragmatic

\footnotetext{
${ }^{1} \mathrm{We}$ are all familiar with instances where non-Western is used as a convenient catch-all term. To mention but two from our own experience: in Leiden University, there was in the 1990s and early 2000s a Centre for Non-Western Studies (CNWS) whose other name was The Research School for African, Asian and Amerindian Studies. Similarly, at the University of Illinois at Urbana-Champaign, undergraduate students are required to study a "nonWestern language chosen from the following list [...]: American Sign Language, Arabic, Bamana, Basque, Chinese, Hebrew, Hindi/Urdu, Japanese, Korean, Lingala, Persian, Quechua, Sanskrit, Swahili, Turkish, Uzbek, Wolof, or Zulu." (source: https://linguistics.illinois.edu/academics/undergraduate-program/degrees-offered/balinguistics; accessed 21/3/19). Readers can come up with similar examples of their own.

${ }^{2}$ Schegloff (1968) is an early paper discussing greetings as serving, through their format, various other functions - though not quite the type of functions we have in mind here.

${ }^{3}$ Outside the three special issues on emancipatory pragmatics (vols. 41:1, 44:5, and 69) published in the Journal of Pragmatics, we have been able to locate only one empirical study conducted in this framework (Donzelli 2010).

${ }^{4}$ For instance, Bianchi (2014: 35) and Cepollaro (2017: 31) acknowledge the importance of Mey's ideas about anticipatory pragmatics (Mey 2012), inspired by the emancipatory pragmatics movement, in their discussions of the appropriation of slurs.
} 
analysis of linguistic behavior beyond their contexts of origin, despite their proponents' aspirations. $^{5}$

Rather, the main way in which non-Western pragmatics continues to be understood is that of taking a concept, a paradigm, or a model developed based on Western modes of thinking and interaction and testing whether it is applicable to non-Western societies. ${ }^{6}$ This applies not only to the 'usual suspects' (the theories of conversational implicature, speech acts, and politeness) but also to recent theoretical advances made within the field of Conversation Analysis. Indeed, non-Western societies have provided fertile grounds for testing these theories. However, overall it would seem that researchers are mostly content when the theories are confirmed and the tendency is to countenance "correction" or "expansion" of tested theories rather than their replacement in the face of disconfirming evidence. The same 'lifting' of practices from a Western context and applying them to non-Western ones can be observed in research practices as well. Ethical principles of data collection and preservation, in particular, have been developed to accommodate ethics as understood in a Western context. We have yet to imagine a research ethics guided by ethical principles as these are understood in other places around the globe.

To illustrate these points, we discuss four themes which have been tested in nonWestern languages. The themes are speech acts (Section 2), conversational implicatures (Section 3), (im)politeness (Section 4), and Conversation Analysis (Section 5). Typically, the tests are inconclusive in the sense that we find studies that confirm and others that diverge from the Western concepts being tested. What this illustrates is that there is diversity of communicative practices, which calls for a plurality of approaches to better theoretically account for the variation that we find. This in turn emphasizes the need for more data and research to be carried out in non-Western contexts, raising the issue of a truly inclusive research ethics. Section 6 highlights how our current practices in this respect can fall short of serving the needs both of the communities where the data is collected, and of the researchers themselves. We conclude with recommending three steps that we can all take to make pragmatics a more inclusive discipline, respecting and reflecting patterns of language-in-use irrespective of where they are located geographically.

\section{Western-centrism in performatives and speech acts?}

Finnegan (1969) investigated performatives in Limba (lia), an Atlantic language of Sierra Leone shortly after speech act theory was proposed by Austin (1962). Finnegan noted that Austin was not the only one to have talked about performatives: social anthropologists had also done so. But she found that Austin had "presented it as a general interpretation of speech rather than as one arising specifically from the study of non-industrial societies or intended to explain distinctive forms such as ritual or 'magical' utterances [...] To follow Austin's analysis thus has the additional merit of taking a concept developed in an industrial context (and a concept, moreover, taken seriously by philosophers) and showing that it is also relevant in a nonindustrial and non-literate community" (1969: 547). Finnegan was thus explicit about showing

\footnotetext{
${ }^{5}$ Hanks et al. write in this regard: "we aim to integrate some of the cross-linguistic variations not only as objects, but also as part of the metalanguage of pragmatic description itself. What would happen, for example, were we to apply a concept like the Japanese wakimae "discernment" to a language like Yucatec Maya or English? Could we productively use the Maya concept of the speaker's body space, called iknal, to describe Japanese, Thai, Lao or Gui? In what way might the |Gui distinctions among pronouns bear on person reference in other languages? What could honorific usage and interpretation in a language like Thai or Japanese tell us about languages like English or Finnish?" (2009: 2).

${ }^{6}$ This view is, reflected, for instance, in Huttar and Gregerson's statement that the rationale for their collection of papers on Pragmatics in non-Western perspectives is "for confirmation, correction, and expansion of ... current models of language and language as used" (1986: viii).
} 
that the concept of performatives developed based on Western philosophy of language applies to a non-Western, non-industrialized lingua-culture. Discussing "performatives" such as pleadings and greetings, she noted that "[w] hat is exchanged in these greetings is both a recognition of the other's position and, as the Limba continually stress, 'honour'," and found that the performative force of the utterances she discussed was more explicit than that of English utterances that had provided the basis for Austin's model. Finnegan concluded that "Austin's theory both of 'performative utterances' and of the wider concept of 'illocutionary acts' fits much better both with their actual practice and with the whole Limba theory of speech."

This may have been the case when one considers the classical concepts of Austin. Later developments concerning indirect speech acts, however, have been more problematic to accommodate in non-Western lingua-cultures. Wierzbicka (2003: 25-65), for example, has argued that different languages and different cultures have different speech acts, which are motivated by different cultural ways of interacting. ${ }^{7}$ Wierzbicka shows how culturally recognized activities of a speaker expressing to an interlocutor or communicative partner "I want you to do something" are realized differently. In Polish, the imperative utterance type is highly valued for expressing this propositional content. In Anglo-American middle-class cultures, such content has to be coded in a way that does not invade the personal sphere or encroach upon the personal autonomy or privacy of the other. Thus, questions (or, to use a classical term, whimperatives) are used. This constraint is relaxed if the act to be carried out is for the benefit of the addressee. But in situations in which the act is for the benefit of the speaker, the imperative is proscribed.

In many non-Western cultures, on the other hand, the imperative utterance type is used irrespective of whose benefit the requested action is for. To illustrate with an activity type (Levinson 1979) that is a common everyday occurrence in most African cultures, recruiting others to help put things on the head so that one can move them from one place to the other, in Ewe, a Kwa language of West Africa, the expressions routinely used have an imperative structure and force, as shown in (1) (from Ameka 2017: 239-242).

a. At the market: S1 a female (porter) aged 18-25; S2 middle aged female (35-40). Relationship: (patron/contractor to carry load; service requester - service provider)

$\begin{array}{ll}\text { lé-e } & \text { ná=m } \\ \text { Hold.3SG } & \text { DAT.3SG }\end{array}$

'Hold it for me' = Help me to put the load on the head

b. In the house: S1 a teenage son carrying a bucket of water on the head from the water well, speaking to the mother

dró=m

put.up/down.1SG

'Put down from head for me'

(= help me put the bucket down from my head)

Similarly, in Cypriot Greek, the variety of Greek spoken on the island of Cyprus, plain $2^{\text {nd }}$ person singular imperative forms are routinely exchanged between interlocutors of various ranks, including employees addressing employers as in (2), and in formal settings, as in (3) (from Terkourafi 2001: 112-113; see also Terkourafi 2005).

\footnotetext{
${ }^{7}$ An earlier version of this work appeared in the Journal of Pragmatics with the title "Different languages, different cultures, different speech acts: English vs. Polish" (Wierzbicka 1985).
} 
(2) (At a paintwork equipment shop; S1: male, aged 18-30, working-class; S2: male, 31-50, middle-class. Relationship: employee-employer)

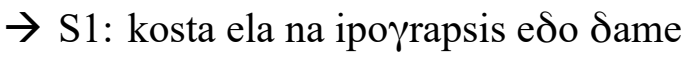

kosta come-2SG to sign-2SG here here-DIAL.

'Kosta come sign here, here.'

((overlapping talk))

(3) (On the radio, RIK1. S1: male, 18-30, middle-class; S2: male, 31-50, middle-class. Relationship: interviewer-interviewee; S1 has been talking about the difficulty of finding a job if during conscription one is characterized by the army as I5 [jota pende])

S1: [eh ine Siaforetika]

$\rightarrow$ S2: [jota pende] pes ti: simeni

S1: e:h anikanos eh stratefsimos

S1: [eh it-is different]

$\rightarrow$ S2: [ai five] say-2SG what it mean-3SG

S1: eh, unfit eh able-to-serve

S1: '[eh, it's different]'

$\rightarrow$ S2: '[ai five] explain what that means'

S1: 'eh, unfit to serve'

Empirical findings such as these have provided the impetus for claiming that, rather than indirectness, what lies at the heart of politeness achieved through language is conventionalization, where the latter is understood as an additional layer of knowledge about the frequency with which linguistic expressions are used to achieve certain ends in context (Terkourafi 2015). On this count, even 'direct' utterances such as those in (1)-(3) can be conventionalized relative to the contexts in which they are frequent. Questioning the canonical understanding of directness in this way echoes the view that "the very concepts of "direct" and "indirect" are just local cultural facts of Standard Average European ethno-pragmatic provenance that make sense within this widespread instrumentalist ideology of semiotic "least effort" and related cultural intuitions" (Silverstein 2010: 338). Indeed, Terkourafi (2014) showed that direct and indirect speech can be indistinguishable in terms of effort invested and effects achieved: either can be effortless and either can produce additional effects. Our claim here is that pragmatics from a non-Western perspective presents an understanding of the use of imperative utterances that is different from what has fed mainstream theories of indirect speech acts. Embracing diversity and not giving universal status to what is a minority practice can hold the key to many future discoveries.

\section{Western-centrism in conversational implicature?}

The Cooperative Principle (CP) and its maxims, proposed by Grice (1989) to account for the logic of conversation, have also been tested in non-Western contexts and found to be nonapplicable. Recall that the earliest critique of the CP, long before it was challenged on theoretical grounds by Sperber \& Wilson (1986), was provided by Keenan (1975) based on ethnographic fieldwork among the Malagasy. Keenan argued that the Malagasy follow very different principles from the maxims of the $\mathrm{CP}$ in communicative interaction. For instance, she 
demonstrated that the first sub-maxim of Quantity, "Make your contribution as informative as is required (for the current purposes of the exchange)," is not adhered to, as speakers do not make explicit reference to events and are prone to withholding significant information from their interlocutors without this prompting the recipients to infer that the speaker is not therefore in possession of the relevant information. It is worth pondering for a moment how that critique was received at the time. After wondering whether that really meant that the $\mathrm{CP}$ was not in operation, scholars concluded that Keenan's findings were actually in support of the CP, since a culture-specific notion known as tsiny (roughly, guilt) operates in Malagasy society, setting expected standards of informativeness (e.g., Cooreman \& Govyaerts 1980: 634; Prince 1982; Fasold 1987: 178; Rohring 2010: 24). Prince (1982: 5) writes in this respect: "If [the recipient] had no Maxim of Quantity and were therefore unable to recognize the flouting of it, it is hard to see how [the speaker] could accrue prestige in [the recipient's] eyes from such an exchange. Thus it seems that, in this case too, Malagasy speakers indeed have a Maxim of Quantity and use it to derive understandings that cannot be logically deduced." Here, then, is an example of how disconfirming evidence can be re-interpreted to fit the theory, rather than motivating a more radical revision.

The Gricean maxim of Manner "Be perspicuous" and its submaxims, furnish further examples of principles which are not adhered to in several non-Western cultures. The four Manner submaxims of the CP cannot readily be interpreted against the requirements of African cultures, as the standards of communication and interaction in these cultures are diametrically opposed to the injunction to "Be perspicuous". Table 1 summarizes the different logics of conversation from a $\mathrm{CP}$ and from an African perspective, as the latter is evidenced in a variety of works that have investigated these phenomena within different African cultures (Ameka 2006, Ayodele 2014, Kondowe et al. 2014, Obeng 1994, 1999, 2003). The differences are immediately obvious.

Table 1: Manner maxims-West vs. Africa

\begin{tabular}{|l|l|l|}
\hline $\begin{array}{l}\text { Cooperative } \\
\text { Principle }\end{array}$ & $\begin{array}{l}\text { Grice's "Way with } \\
\text { Words" }\end{array}$ & $\begin{array}{l}\text { “African ways with } \\
\text { words" }\end{array}$ \\
\hline Supermaxim & Be perspicuous & Be opaque \\
\hline Submaxims & $\begin{array}{l}\text { Avoid obscurity of } \\
\text { expression }\end{array}$ & $\begin{array}{l}\text { Be obscure [Use veiled } \\
\text { speech] }\end{array}$ \\
\hline & Avoid ambiguity & Be ambiguous \\
\hline & $\begin{array}{l}\text { Be brief (avoid } \\
\text { unnecessary prolixity) }\end{array}$ & Be long-winded \\
\hline & Be orderly & Be circuitous \\
\hline
\end{tabular}

Each of these African ways with words is linked to some values, and various modes of communication can be used to illustrate each of them. One could cite various communicative modes and styles to show how much African cultures prefer ambiguous communication. For instance, triadic communication which pervades daily interaction especially in West Africa (Yankah 1995, Ameka 2004) is an equivocal mode of communication in all relevant respects: from participant structure (Irvine 1993) to stance. Similarly, communication with and through objects such as textiles (Beck 2005, Hagan 2010, Yahya-Othman 1997) and potlids (Beck 2004) is also highly opaque. This needs an explanatory theory and it cannot be explained if the discussion is framed in terms of indirectness and other concepts based on Western patterns of language use and logic. What is less often realized is that, in the same way as these linguistic 
practices have been felt to constitute the specific, situated, ethno-cultural identities of these groups, so does discourse which adheres by the Gricean maxims do for Anglo-American cultures. Speaking 'directly' or in accordance with the Gricean maxims is not neutral but itself culturally imbued with meaning and constructs situated, Western, or, more narrowly Anglointeractional identities. What if we turned the tables? What if we took ambiguity, for instance, as the norm in communication? To avoid ambiguity, then, as Grice's Manner maxim instructs us to do, would be a deviation from this norm. This of course requires a radical recasting of what is "maximally efficient exchange of information" (Grice 1989: 28) and how (else) "information" in this quote can be understood, that takes us back to the heart of questions about what meaning is and the truth-conditional tradition in semantics. This is a tall order and it is an open question to what extent it can be done.

\section{Western-centrism in politeness?}

The development of Brown \& Levinson's approach to politeness in the 1970s could be seen as a response to the Anglo/Western-centrism of earlier developments in Speech Act Theory. Their Politeness theory was supposed to be universal and a way of accounting for indirect speech acts, among other things. The firm grounding of their theory in Grice's CP (Brown \& Levinson 1987: 5), however, has been limiting in this respect. For it has led them to seek politeness in increasing rates of indirectness, something which has not been confirmed cross-linguistically (e.g., Blum-Kulka 1987). Moreover, their implicitly emic theorizing has led them to ignore utterances which are actually indirect (by their own criteria of departing from the $\mathrm{CP}$ ) and to classify them as direct ('bald on record') instead. Examples include:

(5) Your slip is showing.

(6) Your headlights are on!

which they classify as "sympathetic advice or warnings" (Brown \& Levinson 1987: 98). In their theory, this move is justified by the fact that the end-beneficiary of any ensuing action is the listener, which may counter-act their face-threatening potential. But it is also apparently oblivious to the fact that, if these utterances are not simply meant as statements but as calls to action, they are as indirect in achieving their goal as the non-conventionally indirect utterances that they classify as off-record indirectness. Soltys et al.'s (2014) proposed term "alerts" aims to capture precisely the 'run-of-the-mill' type of indirectness that these utterances exemplify.

Whether politeness is the same across three blocks in the world, West, East, and Africa, is another controversial matter. Most discussions to date have focused on the West vs. the East (Chen 2010), in which case there have been two camps: those who suggest that there is no radical difference between the two concerning politeness explained in terms of negative and positive face (Brown \& Levinson 1987, Leech 2007), and those who feel strongly that politeness behavior in the East is guided by very different principles than those in the West. In the latter camp, we find researchers such as Matsumoto (1988) and Ide (1989) who, in the wake of Brown and Levinson's theory, proposed that for Japanese the concept of wakimae, translated as 'discernment and attention to one's position in the society', is crucial.

African voices such as Nwoye (1992) and de Kadt $(1994,1998)$ cried out that the individual face and non-imposition strategies of Brown and Levinson are not relevant for African theories of politeness. Rather, for African communities of practice, "social face" or "group face" is more relevant. The guiding behavioral principle is to strive not to do anything that will tarnish the image, dignity, or respect of the group one belongs to, be that a kin group like family or a social group like a social club. Loss of face for the group results in loss of face for the individual and vice versa. While later studies of East Asian societies pointed to 
differences between e.g. the conceptualization of social face in Chinese and in English (Yu 2008), these are not related to the African notion of group face proposed by these scholars. De Kadt has shown how social face in Zulu is linked to cultural values embedded in the behavioral code of hlonipa. ${ }^{8}$ Similar codes across various African communities of practice such as sekuru of the Baatombu of Benin (Schotman 1993), yaage or semteende among different Fulbe groups (Ameka \& Breedveld 2004) and kunya among the Hausa of West Africa (Will 2017), all glossed invariably as respect, restraint, reserve, and so on, relate to group face, insofar as violating these codes reflects badly on one's socialization and therefore one's family. These behavioral codes are about doing things with and for people as well as being with others. They embody ambiguity. They 'define' different first-order politenesses.

It appears that in the case of politeness, non-Western perspectives have had more impact on refining and articulating theories about the phenomenon (e.g., Terkourafi 2012, Kádár and Haugh 2013, among many others). Recently, Jucker (2012: 424) proposed a languageindependent typology of second-order politeness, letting it be an empirical question whether a particular language has these types or not. The first type is discernment, which is not concerned with face-threat mitigation but relates to socially appropriate behavior guided by socio-cultural conventions, similar to Japanese wakimae, although not explicitly related to it. Jucker argues that this is the same as what Watts (2003) calls politic behavior and is concerned with appropriate behavior in socio-cultural and situational context. It does not involve face-threat but rather it is face-maintenance. It seems that this type is similar to what others have called a stasis mode of maintaining face (Arundale 1999) or unmarked politeness (Terkourafi 2001, 2003, 2012). The politeness associated with the behavioral codes of the African communities mentioned above could belong to this type, although one must hasten to add that they do include an element of threat to group face, which also needs to be modeled (see de Kadt 1994 for some suggestions in this direction). The other types of politeness according to Jucker are deference politeness, which relates to the use of titles and honorifics and thus overlaps with the discernment type, and non-imposition strategies, which give the addressee a choice and explicitly express non-intrusion and non-coerciveness on the addressee's wishes. Notably, a solidarity, face-enhancing mode of politeness, as claimed, for instance, for Spanish (Bravo 1999), Turkish (Bauraktaroglu 1991), or Greek (Sifianou 1992), is still absent from this model. It is possible that in most non-Western communities, as opposed to contemporary Anglosocieties, non-imposition politeness plays only a small part. In fact, Jucker (2012) shows that this was the case even for different stages in the history of English. In Anglo-Saxon England, for instance, there was no evidence of non-imposition politeness, although there is a heavy reliance on it in Present Day English. ${ }^{9}$ Terkourafi (forthcoming) explores the hypothesis that globalization and a weakening of network ties leads to more explicitness in communication as the shared common ground decreases. She uses changes among generations of African American women, and in compliment responses in Chinese discourse among the case studies supporting this hypothesis. It would be interesting to find out whether this hypothesis holds also in non-Western contexts such as Africa, where implicit communication is the norm and urbanization and globalization are on the rise, and what this means for im/politeness interactions in these contexts. It is not inconceivable that a real loss in communicative diversity may be occurring under pressure from Western modes of communication brought about by globalization.

\footnotetext{
${ }^{8}$ See also Herbert (1990) and Finlayson (2004). Avoidance respect registers have also been documented for the Datoga of Tanzania (Mitchell 2015, 2018) and among the Highland East Cushitic languages of Ethiopia (Treis (2005).

${ }^{9}$ According to Culpeper \& Demmen (2011), the focus on non-imposition in British English is a $19^{\text {th }}$ century phenomenon associated with the rise of the individual self.
} 


\section{Western-centrism in Conversation Analysis?}

The field of Conversation Analysis would appear to be the least vulnerable to the critique of western-centrism frequently leveled against the theories dealt with above, and to some extent that is true. Clearly, the field's origins in sociology and ethnomethodology have something to do with this. It is worth remembering, however, that Sacks' seminal insights that are at the foundations of the field (Sacks 1992) also originated in a Western (specifically, US) context and the same goes for the core terminology used. It has therefore been apposite to test these in a number of different lingua-cultures and this is happening increasingly through a large number of projects across the globe, including some based in Africa (e.g. Dingemanse 2015, in press). These projects have led to some fascinating insights.

In the past decade, scholars at the Max Planck Institute in Nijmegen have undertaken cross-linguistic and cross-cultural investigations of a number of pragmatic phenomena including speech acts such as questions (Enfield, Stivers \& Levinson 2010), other-initiated repair (Dingemanse \& Enfield 2015), and turn-taking (Holler et al. 2016) - aiming to produce pragmatic typologies of systems of language use and the principles that shape them. The assumption is that some aspects of language use are species-specific and should be considered part of the human 'interaction engine' (Levinson 2006) at the base of human sociality, and therefore 'universal'. The goal of pragmatic typologies, then, is to discover the range of possibilities for performing these practices (e.g., Dingemanse et al. 2014). Yet, even this pioneering work has taken for granted some basic assumptions founded in Western practice that may not always be defensible. One such assumption is intentionality. In a recent anthropological critique of this notion, Robins and Rumsey note, that "even if it is true that the capacity for inferring the mental states of others is a generically human one, and plays a part in communication everywhere, it does not follow that all language ideologies will give it equal prominence, or even allow it to be openly recognized or actualized in speech" (2008: 414). As such, Enfield and Levinson's strongly stated assumption that "the roots of human sociality ... crucially involv[e] intention attribution" (2006: 9) ${ }^{10}$ despite coming hedged with the additional comment that "there may be cultures with distinctly different ideas about the readability of others' intentions" (2006:19) can still appear "ethnocentric" (Robins and Rumsey 2008: 413) or, at least, somewhat axiomatic.

There is no doubt that the methodological shift from philosophy and constructed examples to close examination of naturally-occurring interactions has already shifted pragmatics away from many Anglo/Western philosophically-driven assumptions. Without downplaying the importance of this work, it is also important to acknowledge that the directionality of influence has remained unchallenged: what are tested in non-Western contexts are often notions that were first theorized about in Western ones. To what extent these can be treated as a-cultural and therefore theoretically 'portable' remains an open question.

In an important critique of the seminal notion of "casual conversation", Gaudio (2003) argued that even this seemingly unqualified notion is locally constructed and culturally invested through and through. The same goes for another key term, "face-to-face" interaction. There is no shortage of literature showing that different cultures have different communicative styles and ways of being with one another in the same place. In particular, it has been shown that in many cultures people do not position themselves face-to-face nor do they look each other in the eye (Walsh 1997). This means that "face-to-face communication" is an inappropriate and inadequate term to use for when people are in the same place and doing things with words with

\footnotetext{
${ }^{10}$ To be fair, not all CA practitioners would agree with this view. Maynard (2013:28) asserts that CA is agnostic about "cognitive maxims, intentions and other psychological features that are said to explain the meaning of utterances". Similarly, Stivers (2013:208) notes that CA's analysis of social interaction and language use is structured around "social and relational concerns rather than cognitive ones" (cf. also Drew 2018).
} 
one another. Goffman (1981) observed this long ago and described it as "co-present communication". This is a more inclusive term that does not privilege what is the norm in Western societies over what happens in some non-Western contexts. Yet, the term "face-toface" continues to be unproblematically used seemingly without any awareness of its cultural underpinnings. ${ }^{11}$

At the same time, key theoretical insights in the field continue to originate from Western settings. An opportune example is the notion of recruitments, recently proposed as a superordinate category of the (linguistically realized) category of requests. This is a groundbreaking notion that recalibrates the focus on language, treating it as one modality among many through which recruitments can be done. ${ }^{12}$ Although attention to the phenomenon was drawn within a project that included African, Asian and European languages (Floyd et al. 2014), in the seminal volume that introduced this notion (Drew \& Couper-Kuhlen 2014), all but one of twelve empirical contributions deal with Western languages. ${ }^{13}$ This is by no means a sin but it should alert us to the possibility that, while theoretical progress is undoubtedly being made, there is a danger that the West remains the ruler by which the rest of the world is measured, while non-Western perspectives continue to be marginalized in this respect. It is clear how this can be limiting: Western perspectives are not un-situated or culturally neutral: rather, they are themselves situated in a Foucauldian way, rooted in Western ways of experiencing the world and continuous monitoring is required to ensure that they do not provide the 'glasses' through which (Western-trained) linguists deal with data from non-Western languages. ${ }^{14}$ In the case of Conversation Analysis, the field's stern insistence on theoretical accountability and firm grounding in the observable details of talk-in-interaction is meant to safeguard from this. More can (and should) be done to ensure the kind of "cognitive justice" we are advocating here.

\section{Western-centrism in methods and ethics}

We started out by suggesting that in the interest of cognitive justice, pragmatics as a discipline cannot continue to ignore theoretical insights and patterns of language use emanating from nonWestern societies. A corollary of this is that it is not ethical for the discipline to continue to use non-Western societies (however defined) simply as a testing-ground for theories and tools developed based on Western patterns of language use. As several disciplines are experiencing (and experimenting with) the rise of citizen science as a way of giving equal status to research participants, it is time for pragmatics researchers too to empower not only the viewpoints of non-Western participants but the participants themselves.

Data collection in pragmatics may involve work in the laboratory (Experimental Pragmatics) or interaction with language users in different contexts in their communities, i.e. various forms of fieldwork. These methods are not mutually exclusive and involve some ethical considerations. A fundamental ethical principle is that the conduct and products of our research should not be harmful in any way or form to the participants in the research. An important ethical question in this context is the extent to which a researcher can reveal personal information about research participants without exposing them to harm. Pragmatics is concerned with actual language use by real people in socio-cultural contexts. As language use

\footnotetext{
${ }^{11}$ For instance, "face-to-face" is the standard term used in the Drew \& Couper-Kuhlen (2014) volume discussed next.

${ }^{12}$ Although see Heritage (2016) on differences between recruitments and more "language heavy" requests.

${ }^{13}$ The languages are English, Danish, Finnish, French, German, Italian and Swedish. The non-Western language analyzed is Lao. Even the chapter comparing orangutans and human infants specifies that language data are from "middle-class Western human infants" (Rossano \& Liebal 2014: 355).

${ }^{14}$ Brown and Levinson's 'color-blindedness' when it came to theorizing "alerts" discussed in the previous section is an apt example of how one's culture inevitably provides the glasses through which one approaches the world, including scientific theorizing.
} 
is multimodal, the optimal data for pragmatic analysis is data recorded in audio-visual media. Such recordings carry the imprint of the data providers: their voice, their appearance, their gait etc. Could making public this information, which is personal in nature, be detrimental to participants? To circumvent this problem, it is generally suggested that researchers should anonymize the data before making them public. Anonymization takes several forms: using pseudonyms, removing participants' personal names and using tags to identify them; distorting their voices and blurring their images in videos.

Such solutions are largely guided by Western ideas of ethics, which prize autonomy and privacy (a Western notion par excellence). But how respectful are they to the participants with whom the data have been co-produced? In some communities, research participants are happy, indeed expect, to be fully identified. However, ethical requirements imposed by external legal systems, and in the case of most non-Western societies, by Western systems of practice, work against such identification. The challenge here is that a researcher must also cite and attribute data and give credit to the participants who generated the data and such ethical principles of reciprocity can also be highly valued. A related consideration that has not yet been given due attention is the extent to which anonymization practices allow the researcher to do this in an ethical way according to local ethical standards. Note that this is not a trivial matter, as it can impact researcher-participant relations in the long-term.

Anonymizing data has consequences for scientific enquiry as well. For the researcher, removal of identifiable details from the voice and visuals distorts the data. It also makes it hard to verify and replicate the research findings. Let us illustrate with a case from a language documentation and socialization project in Papua New Guinea. ${ }^{15}$ In a language learning session, the child, a boy, sticks out his tongue towards the mother. This is a very significant pragmatic act and an interesting one for researchers of socialization and pragmatics. The scene is captured on video by the family during one of their recording sessions. However, because of requirements of not revealing identifiable information on videos especially involving children (despite informed consent by the family) the video has to be blurred (see http://qaqet.philfak.uni-koeln.de/37149.html). How can the gesture be verified? How can this video be used to make any claims about the significance and use of the gesture? If theoretical advances are supposed to come precisely from this enlarged pool of materials, the value of these materials to researchers is rendered close to nil by current, western-inspired ethics practices. Clearly, this critique applies to linguistic fieldwork in general and is not just limited to pragmatics. We discuss it here, nevertheless, because the relevant problems are a symptom of the same tendency to treat Western concepts (in this case, Western notions of ethics and of what is important to people) as culturally neutral and therefore as applicable in all contexts.

\section{Imagining a more inclusive pragmatics}

There is a slow realization in the language sciences that language universals including universals of pragmatics built on a narrow empirical base grounded in Western ways with words and practices are a myth (Evans and Levinson 2009, Levinson and Evans 2010, Heinrich et al. 2010, Eisenbeiss and Hellwig 2018). Rather, variation and diversity are the hallmark of the human language system. As Levinson (2012: 397) puts it: "there is no other animal on the planet, as far as we know, which has such myriad variants of form and meaning at every level in its communication system" (cf. Tomasello 2008: 299). In their response to commentaries on their 2009 paper on the myth of language universals, Levinson and Evans (2010) call for a sea change in linguistics where variation and diversity of systems are given more prominence than universals. What applies to linguistics in general applies even more so to pragmatics, the study

\footnotetext{
${ }^{15} \mathrm{We}$ are very grateful to Birgit Hellwig of the University of Cologne for sharing this information and allowing us to use it.
} 
of actual language-in-use. There is the need for a sea change in how pragmatics is researched, theorized and described.

We are under no illusion that any of the theories discussed above can by itself contain and describe reality in all its complexity and from all perspectives. Like the 'Western' theories they are aspiring to replace, or at least, enrich, non-Western pragmatic perspectives are also situated in a Foucauldian fashion in the knowledge systems from which they emanate, and necessarily only offer partial views of reality. That is why we need all of them (and more!) to "embrace" the tree - to recall the Ewe proverb at the start of this paper. In closing, we offer three recommendations by way of small steps that we can all apply in our daily work in order to try to achieve this.

First, we should refrain from assuming that ideas, language practices and patterns of use in Western societies are universals of language use among humans and (can/should) provide the point of departure for describing language practices elsewhere. Liberating ourselves from this assumption could have a refreshing effect on the theoretical insights we can come up with.

Second, we should use more inclusive terminology and metalanguage in the description of language use across cultures. ${ }^{16}$ Our highlighting the limitations of "face to face" to describe co-present communication above is one example of that. More should be done to ensure researchers are aware of the cultural underpinnings of the terms they use, and specifically of the problems of using English as a scientific metalanguage, along the lines discussed by Wierzbicka (2014) and Haugh (2016).

Lastly, to achieve greater representativeness, pragmatics researchers should pay attention to variation in patterns of language use across multiple modalities and multiple contexts in their theorizing. It is very likely that languages partition information differently across modalities and sophisticated methodologies raising complex ethical issues are needed to capture the necessary data. Some of the above is already happening. Our hope is that the wave will become a tide.

\section{Acknowledgements}

We are grateful to three anonymous referees, whose comments significantly helped us improve this paper. All remaining errors are our own.

\section{Abbreviations}

The following abbreviations are used in the interlinear glosses: $1=$ first person; $2=$ second person; 3 = third person; CFM = clause final marker; DIAL = dialectal; DAT $=$ dative; IDEO $=$ ideophone; $\mathrm{PL}=$ plural; $\mathrm{REL}=$ relative clause introducer; $\mathrm{SG}=$ singular; = equal sign indicates clitic boundary; - hyphen indicates morpheme boundary; : = elongated sound; $[\ldots]=$ overlapping speech; $(())=$ transcriber comment; $\rightarrow=$ indicates the line commented on in the text

\section{References}

Ameka, Felix K. 2004. Grammar and cultural practices: The grammaticalisation of triadic communication in West African languages. The Journal of West African Languages 30(2): 5-28

\footnotetext{
${ }^{16}$ With respect to this point, a reviewer suggests that we may focus on emic linguistic practices, as scholars like Wierzbicka have done. However, the Natural Semantic Metalanguage is not the kind of inclusive terminology we have in mind here for the reason that emic terms (good, I, you, etc.) as used by, e.g., Wierzbicka (2014) and Goddard (2006), to explicate complex emic concepts (speech acts etc.) are used as terms of the NSM and do not reflect the practices of participants themselves when called to describe these phenomena. Rather, our point is more akin to Anchimbe's (2018: 7) aim is to attract more "emic pragmatic research attention to these [in his case, postcolonial] societies."
} 
Ameka, Felix K. 2006. 'When I die, don't cry': the ethnopragmatics of gratitude expressions in West African languages. In Cliff Goddard (ed.) Ethnopragmatics. 234-266. Berlin: Mouton de Gruyter

Ameka, Felix K. 2009. Access rituals in West Africa: an ethnopragmatic perspective. In Gunter Senft \& Ellen Basso (eds.), Ritual Communication, 127-155. Oxford: Berg

Ameka, Felix K. 2017. Meaning between algebra and culture: Auto antonyms in the Ewe lexicon. In Reckman, Hilke, Lisa L.S. Cheng, Maarten Hijzelendoorn \& Rint Sybesma (eds.), Crossroads Semantics: Computation, experiment and grammar, 227-248. Amsterdam: John Benjamins.

Ameka, Felix K \& Anneke O. Breedveld. 2004. Areal cultural scripts for social interaction in West African communities Intercultural Pragmatics 1(2). 167-187.

Anchimbe, Eric. 2018. Offers and Offer Refusals: A Postcolonial Pragmatics Perspective on World Englishes. Amsterdam: John Benjamins.

Anchimbe, Eric \& Richard Janney (eds.). 2011. Postcolonial Pragmatics. Special issue Journal of Pragmatics 43(6): 1451-1539.

Anchimbe, Eric \& Richard Janney. 2017. Postcolonial pragmatics. In Barron, Anne, Yueguo Gu \& Gerard Steen (eds.), The Routledge Handbook of Pragmatics, 105-120. London: Routledge.

Arundale, Robert. 1999. An alternative model and ideology of communication for an alternative to politeness theory. Pragmatics 9:.119-153.

Austin, John L. 1962. How to Do Things with Words. Oxford: Clarendon Press.

Ayodele, Ayo. 2016. OMOLUWABI: Towards a theory of cooperation in Yoruba interactional discourse practices. In Traore, Karim, Solunsa, Mobolanle \& Ojo, Akinloye (eds.) Expressions of Indigenous and Local Knowledge in Africa and its Diaspora, 80 90. Newcastle Upon Tyne: Cambridge Scholars Publishing.

Bayraktaroğlu, Arın. 1991. Politeness and interactional imbalance. International Journal of the Sociology of Language 92. 5-34.

Beck, Rose Marie. 2004. Speaking potlids from the Lower Congo (Cabinda/Angola). In Beck, Rose Marie \& Wittmann, Frank (eds.) African Media Cultures. Transdisciplinary Perspectives-Cultures de Médias en Afrique. Perspectives Transdisciplinaires, 99-122. Cologne: Rudiger Köppe

Beck, Rose Marie. 2005. Texts on textiles: proverbiality as characteristic of equivocal communication at the East African coast (Swahili)." Journal of African Cultural Studies 17(2). 131-160.

Bianchi, Claudia. 2014. Slurs and appropriation: An echoic account. Journal of Pragmatics 66: $35-44$.

Blum-Kulka, Shoshana. 1987. Indirectness and politeness in requests: Same or different? Journal of Pragmatics 11. 145-160.

Bravo, Diana. 1999. Imagen 'positiva' vs. imagen 'negativa'? Pragmática sociocultural y componentes de face. Oralia 2.122-184.

Brown, Penelope \& Stephen C. Levinson 1987. Politeness: Some Universals in Language Usage. Cambridge: Cambridge University Press.

Cepollaro, Bianca. 2017. When evaluation changes: An echoic account of appropriation and variability. Journal of Pragmatics 117. 29-40.

Chen, Rong. 2010. Pragmatics between East and West: Similar or different? In Trosborg, Anna (ed.) Pragmatics acrross Languages and Cultures, 167-188. Berlin: De Gruyter.

Cooreman, A. \& Didier Goyvaerts. 1980. Universals in human language: A historical perspective. Revue belge de Philologie et d'Histoire 58(3). 615-638. 
Culpeper, Jonathan, and Jane Demmen. "Nineteenth-century English politeness: Negative politeness, conventional indirect requests and the rise of the individual self." Journal of Historical Pragmatics 12, no. 1 (2011): 49-81.

De Kadt, Elizabeth. 1994. Towards a model for the study of politeness in Zulu. South African Journal of African Languages 14(3). 103-112.

De Kadt, Elizabeth. 1998. The concept of face and its applicability to the Zulu language Journal of Pragmatics 29(2).173-191.

Dingemanse, Mark. 2015. Other-initiated repair in Siwu. Open Linguistics 1(1). 232-255. doi:10.1515/opli-2015-0001.

Dingemanse, Mark. in press. Recruiting assistance in interaction: a West-African corpus study. In Getting others to do things: A pragmatic typology of recruitments. Berlin: Language Science Press.

Dingemanse, Mark \& Nick J. Enfield (eds.) 2015. Other-initiated repair across languages: Towards a typology of conversational structures. Open Linguistics 1.

Dingemanse, Mark, Joe Blythe, \& Tyko Dirksmeyer. 2014. Formats for other-initiation of repair across languages: An exercise in pragmatic typology. Studies in Language 38(1): 543.

Donzelli, Aurora. 2010. Is ergativity always a marker of agency? Toraja and Samoan grammar of action and the contribution of emancipatory pragmatics to social theory. Applied Linguistics Review 1. 193-220.

Drew, Paul. 2018. Inferences and indirectness in interaction. Open Linguistics 4: 241-259.

Drew, Paul \& Elizabeth Couper-Kuhlen(eds.) 2014. Requesting in Social Interaction. Amsterdam: John Benjamins.

Eisenbeiss, Sonja \& Birgit Hellwig. 2018. Extending psycholinguistics to under-represented languages and populations-The principle of justice and ethical challenges for new types of linguistic fieldwork. Ms. University of Cologne.

Enfield, Nicholas J. \& Stephen C. Levinson (eds.) 2006. Roots of Human Sociality: Culture, Cognition and Interaction. London: Bloomsbury.

Enfield, Nicholas J., Tanya Stivers \& Stephen C. Levinson. 2010. Question-response sequences in conversation across ten languages: An introduction Journal of Pragmatics 42(10). 2615-2619

Evans, Nicholas \& Stephen C. Levinson. 2009. The myth of language universals: Language diversity and its importance for cognitive science. Behavioral and Brain Sciences 32(5). 429-448.

Fasold, Ralph. 1987. The Sociolinguistics of Language. Vol. 2. Oxford: Blackwell.

Finnegan, Ruth. 1969. How to do things with words: performative utterances among the Limba of Sierra Leone. Man 4(4). 537-552.

Finlayson, Rosalie. 2004. Women's language of respect isihlonipha sabafazi. In Rajend Mesthrie (ed.) Language in South Africa, 279-296. Cambridge University Press

Floyd, Simeon, Giovanni Rossi, Nick Enfield, Julija Baranova, Joe Blythe, Mark Dingemanse, Kobin Kendrick and Jörg Zinken. 2014. Recruitments across languages: A systematic comparison. Presented at the 4th International Conference on Conversation Analysis, University of California at Los Angeles, CA.

Foley, William. 1997. Anthropological Linguistics. Oxford: Blackwell.

Gaudio, Rudolf. 2003. Coffeetalk: Starbucks ${ }^{\mathrm{TM}}$ and the commercialization of casual conversation. Language in Society 32(5), 659-691.

Goddard, Cliff (ed.) 2006. Ethnopragmatics. Berlin: Mouton de Gruyter.

Goffman, Erving. 1981. Forms of Talk. Philadelphia: University of Pennsylvania.

Grice, Herbert Paul. 1989. Studies in the Way of Words. Cambridge MA: Harvard University Press. 
Hagan, Martha A. 2010. Speaking Out: Women, Pagne, and Politics in the Cote D'Ivoire. The Howard Journal of Communications 21(2). 141-163.

Hanks, William, Sachiko Ide \& Yasuhiro Katagiri. 2009. Towards an emancipatory pragmatics. Journal of Pragmatics 41(1). 1-9.

Haugh, Michael. 2016. The role of English as a scientific metalanguage for research in pragmatics: Reflections on the metapragmatics of "politeness" in Japanese. East Asian Pragmatics 1 (1). 39-71.

Henrich, Joseph, Steven J. Heine \& Ara Norenzayan. 2010. The weirdest people in the world. Behavioural and Brain Sciences 33(2/3).61-83.

Herbert, Robert K. 1990. Hlonipha and the ambiguous woman. Anthropos (4/6). 455-473.

Heritage, John. 2016. The recruitment matrix. Research on Language and Social Interaction 49. 27-31.

Holler, Judith, Kobin H. Kendrick, Marisa Casillas, \& Stephen C. Levinson. 2016. Turn-taking in Human Communicative Interaction. Lausanne: Frontiers Media.

Huttar, George, \& Kenneth Gregerson. 1986. Pragmatics in Non-Western Perspective. Dallas, TX: Summer Institute of Linguistics.

Ide, Sachiko. 1989. Formal forms and discernment: Two neglected aspects of universals of linguistic politeness. Multilingua 8(2-3). 223-248.

Irvine, Judith. T. 1974. Strategies of status manipulation in the Wolof greeting. In Bauman Richard and Joel Sherzer (eds.) Explorations in the Ethnography of Speaking, 167-191. Cambridge: Cambridge University Press.

Irvine, Judith T. 1993. Insult and responsibility: Verbal abuse in a Wolof village. In Hill, Jane H. and Judith T. Irvine (eds.) Responsibility and Evidence in Oral Discourse, 105-134. Cambridge: Cambridge University Press.

Jucker, Andreas. 2012. Changes in politeness cultures. In Terttu Nevalainen, Elizabeth Closs Traugott (eds.) The Oxford Handbook of the History of English, 422-433. Oxford: Oxford University Press.

Kádár, Daniel Z. \& Michael Haugh. 2013. Understanding Politeness. Cambridge University Press.

Keenan, Elinor Ochs. 1976. The universality of conversational postulates. Language in Society 5(1). 67-80.

Kondowe, Wellman, Flemmings, Fishani Ngwira, \& Precious Madula. 2014. Linguistic analysis of Malawi political newspaper cartoons on President Joyce Banda: Towards Grice's conversational implicature. International Journal of Humanities and Social Science 4(7). 140-151

Leech, Geoffrey. 2007. Politeness: is there an East-West divide? Journal of Politeness Research 3(2). 167-206.

Levinson, Stephen C. 1979. Activity types and language. Linguistics 17. 365-399.

Levinson, Stephen C. 2006. On the human 'interaction engine'. In Enfield, Nicholas J and Stephen C. Levinson (eds.), Roots of Human Sociality. Culture, Cognition and Human Interaction, 39-69. Oxford: Berg.

Levinson, Stephen C. 2012. The original sin of cognitive science. Topics in Cognitive Science 4(3). 396-403.

Levinson, Stephen C. \& Nicholas Evans. 2010. Time for a sea-change in linguistics: Response to comments on 'The myth of language universals'. Lingua 120(12). 2733-2758.

Matsumoto, Yoshiko. 1988. Reexamination of the universality of face: Politeness phenomena in Japanese. Journal of Pragmatics 12(4). 403-426.

Maynard, Douglas W. 2013. Everyone and no one to turn to: Intellectual roots and contexts for Conversation Analysis. In Sidnell, Jack \& Stivers, Tanya (eds.) The Handbook of Conversation Analysis, 11-31. Oxford: Blackwell 
Mey, Jacob. 2012. Anticipatory pragmatics. Journal of Pragmatics 44(5). 705-708.

Mitchell, Alice. 2015. Words that smell like father-in-law: A linguistic description of the Datooga avoidance register. Anthropological Linguistics 57(2): 195-217.

Mitchell, Alice. 2018. Allusive References and Other-Oriented Stance in an Affinal Avoidance Register. Journal of Linguistic Anthropology 28(1). 4-21.

Mukaro, Laston, Victor Mugari, \& Annastacia Dhumukwa. 2013. Violation of conversational maxims in Shona. Journal of Comparative Literature and Culture (JCLC) 2(4). 161-168.

Nwoye, Onuigbo. 1992. Linguistic politeness and socio-cultural variations of the notion of face. Journal of Pragmatics 18 (4). 309-328.

Obeng, Samuel Gyasi. 1994. Verbal indirection in Akan informal discourse. Journal of Pragmatics 21(1). 37-65.

Obeng, Samuel Gyasi. 1999. "In future if 1 buy a dog, l'll call it 'Okyeman-is-ungrateful'." Indirect response to potentially difficult communicative situations: the case of Akan dog names. International Journal of the Sociology of Language140(1). 83-104.

Obeng, Samuel Gyasi. 2003. Language in African social interaction: Indirectness in Akan communication. Nova Science Pub Inc.

Prince, Ellen. 1982. Grice and universality: a reappraisal. Ms. University of Pennsylvania.

Robbins, Joel \& Alan Rumsey. 2008. Introduction: Cultural and linguistic anthropology and the opacity of other minds. Anthropological Quarterly 81(2). 407- 420.

Rossano, Federico and Katja Liebal. 2014. Requests and offers in orangutans and human infants. In Drew, Paul and Elizabeth Couper-Kuhlen (eds.) Requesting in Social Interaction, 335-364. Amsterdam: John Benjamins

Sacks, Harvey. 1992. Lectures on Conversation. Oxford: Blackwell.

Schegloff, Emmanuel A. 1968. Sequencing in Conversational Openings. American Anthropologist 70. 1075-1095.

Schotman, Wendy. 1993. Proverbial dog names of the Baatombu: A strategic alternative to silence. Language in Society 22(4). 539-554.

Senft, Gunter. 2014. Understanding Pragmatics. Hoboken: Taylor and Francis.

Sifianou, Maria. 1992. The Use of Diminutives in Expressing Politeness: Modern Greek versus English. Journal of Pragmatics 17. 155-173.

Silverstein, Michael. 2010. "Direct" and "indirect" communicative acts in semiotic perspective. Journal of Pragmatics 42(2): 337-353.

Soltys Jessica, Terkourafi Marina \& Napoleon Katsos. 2014. Disentangling politeness theory and the strategic speaker approach. Intercultural Pragmatics 11(1): 31-56.

Sperber, Dan \& Deirdre Wilson. 1986. Relevance: Communication and Cognition. Oxford: Blackwell.

Stivers, Tanya. 2013. Sequence organisation. In Sidnell, Jack \& Stivers, Tanya (eds.) The handbook of conversation analysis, 191-209. Oxford: Blackwell

Terkourafi, Marina. 2001. Politeness in Cypriot Greek: A Frame-Based Approach. PhD Dissertation, University of Cambridge.

Terkourafi, Marina. 2005. An argument for a frame-based approach to politeness: evidence from the use of the imperative in Cypriot Greek. In Lakoff, Robin and Sachiko Ide (eds.) Broadening the Horizon of Linguistic Politeness, 99-116. Amsterdam: John Benjamins.

Terkourafi, Marina, 2012. Politeness and pragmatics. In Jaszczolt, K. \& Allan, K. (eds.) The Cambridge Handbook of Pragmatics, 617-637. Cambridge: Cambridge University Press.

Terkourafi, Marina. 2014. The importance of being indirect: A new nomenclature for indirect speech. Belgian Journal of Linguistics 28(1). 45-70.

Terkourafi, Marina. 2015. Conventionalization: A new agenda for im/politeness research. Journal of Pragmatics, 86. 11-18. 
Terkourafi, Marina. forthcoming. Indirectness in the age of globalisation: a variational pragmatics perspective. Russian Journal of Linguistics. Special issue on (Im)politeness in global contexts.

Tomasello, Michael. 2008. Origins of Human Communication. Cambridge, Mass.: MIT Press.

Treis, Yvonne. 2005. Avoiding their names, avoiding their eyes: How Kambaata women respect their in-laws. Anthropological Linguistics 47(3). 292-320.

Visvanathan, Shiv. 2002. The future of science studies. Futures 34(1). 91-101.

Walsh, Michael. 1997. Cross Cultural Communication Problems in Aboriginal Australia. North Australia Research Unit, The Australian National University, Darwin.

Watts, Richard J. 2003. Politeness. Cambridge: Cambridge University Press.

Wierzbicka, Anna. 1985. Different languages, different cultures, different speech acts: English vs. Polish. Journal of Pragmatics 9. 145-178.

Wierzbicka, Anna. 2003. Cross-cultural Pragmatics: The Semantics of Human Interaction. (Second edition) Berlin: Mouton.

Wierzbicka, Anna. 2014. Imprisoned in English. New York: Oxford University Press.

Will, Izabela. 2017. Programmed by culture? Why gestures become the preferred ways of expressing emotions among the Hausa. In Storch, Anne (ed.) Consensus and Dissent: Negotiating Emotion in the Public Space, 123.-145. Amsterdam: John Benjamins

Yahya-Othman, Saida 1997. If the cap fits: Kanga names and women's voice in Swahili society. Swahili Forum IV, 52. 135-149.

Yankah, Kwesi. 1995. Speaking for the chief. Bloomington: Indiana University Press

$\mathrm{Yu}$, Ning. 2008. Metaphor from body and culture. In R. W. Gibbs (ed.) The Cambridge handbook of metaphor and thought, 247-261. Cambridge: Cambridge University Press. 